\title{
LA REALIDAD PERSONAL EN PERSPECTIVA NEUROCIENTÍFICA. LA APORTACIÓN ZUBIRIANA ${ }^{1}$
}

\author{
JESÚS CONILL SANCHO \\ Universidad de Valencia
}

\begin{abstract}
RESUMEN: El artículo muestra que el concepto de persona, el tipo de realidad personal elaborado por Zubiri, constituye una importante aportación filosófica en el actual contexto de la neurociencia, porque su filosofía de la persona está conectada con las ciencias biológicas y especialmente con una concepción del cerebro humano, que es entendido como órgano de hiperformalización y proporciona la base de su nuevo concepto de inteligencia sentiente, más allá de las tradicionales concepciones de la substancia, la conciencia y el sujeto.
\end{abstract}

PALABRAS CLAVE: Persona, Realidad, Cerebro, Hiperformalización, Conciencia, Sujeto, Cuerpo, Inteligencia sentiente, Zubiri.

\section{Personal Reality in the Neuroscientific Perspective. The Contribution of Zubiri}

ABSTRACT: The article shows that the concept of personhood, the type of reality of person elaborated by Zubiri, represents an important philosophical contribution in the current context of neurosciences, because his philosophy of personhood is connected with biological sciences and especially with a conception of human brain, which is understood as organ of hyperformatilzation and provides the basis for grounding the new concept of sentient intelligence, beyond the traditional conceptions of substance, consciousness and subject.

KEY WORDS: Personhood, Reality, Brain, Hyperformalization, Consciousness, Subject, Body, Sentient Inteligence, Zubiri.

\section{LA ACTUAL PERSPECTIVA NEUROCIENTÍFICA}

En los últimos decenios se ha producido una creciente expansión de los estudios neurológicos y con ella se ha extendido a su vez la idea de que con el nuevo conocimiento científico que aportan se podrán solucionar los persistentes problemas filosóficos que se arrastran desde antiguo. Algunos neurocientíficos utilizan conceptos tradicionalmente filosóficos, pero con un contenido sacado al parecer exclusivamente de las ciencias. Se lleva a cabo así un consciente reduccionismo ${ }^{2}$, en el que quedan eliminadas cualesquiera entidades que no se atengan al control exclusivo del conocimiento científico.

1 Este estudio se inserta en el Proyecto de Investigación Científica y Desarrollo Tecnológico FFI2013-47136-C2-1-P, financiado por el actual Ministerio de Economía y Competitividad y con Fondos FEDER de la Unión Europea, y en las actividades del grupo de investigación de excelencia PROMETEO 2009/085 de la Generalidad Valenciana.

2 Bennett, M.R. y Hacker, P.M.S., Philosophical Foundations of Neuroscience. Oxford: Blackwell, 2003. 
El tradicional espacio filosófico está siendo ocupado cada vez más por neurocientíficos y tecnocientíficos, que han logrado imponer un nuevo horizonte intelectual con relevancia en la vida práctica y gran audiencia mediática, en el que se combinan elementos neuroculturales y tecnoculturales. Por este camino quedaría atrás la estéril "paleofilosofía» de los tiempos antiguos y modernos, que acaba convirtiéndose en mera historia de la filosofía.

Una de las líneas más influyentes ha sido la promovida por Patricia S. Churchland, que ha pretendido reducir explícitamente los problemas filosóficos a los neurológicos mediante una revalidación del intento neopositivista de una ciencia unificada, ahora desde la neurología: «La neurociencia va conformando nuestra concepción de lo que somos». «Es el cerebro (...) lo que siente, piensa y decide». "Ahora entendemos que esos importantes sentimientos [amor, etc.] son sucesos que ocurren en el cerebro físico ${ }^{3}$. Con lo cual la mente se reduciría a la actividad del cerebro mismo. La mente como tal no existiría, lo único de lo que habría constancia en relación a los procesos mentales serían los correspondientes procesos de actividad neuronal.

Una primera característica de este proyecto es la de ofrecer una nueva forma de naturalismo filosófico, ahora en versión neurofisiológica, que se autodenomina «neurofilosofía» y que, por tanto, constituye una interpretación de la realidad, también de la realidad humana. Pero, más que de un resultado auténticamente científico se trata de un producto hermenéutico.

Esta actitud de gran parte de los neurocientíficos implica un determinado modo de entender la relación entre ciencia y filosofía; pero antes de establecerla como incontestable habría que debatir explícitamente mediante reflexión crítica cuál es la concepción más adecuada de tal relación. Pues, si la filosofía queda sustituida por la ciencia y el único conocimiento es el que proviene de las ciencias, por ejemplo, de las neurociencias, entonces la filosofía queda vaciada de sus conceptos tradicionales, los cuales tendrían que ser explicados ahora por la nueva investigación neurocientífica. En cambio, si la relación entre filosofía y ciencia no es de sustitución de la primera por la segunda, sino que se mantiene el estatuto de ambas en su especificidad, entonces habrá que ver cómo se complementan las aportaciones de cada una de ellas, como veremos que ocurre en la filosofía de Zubiri.

Por otra parte, una característica de buena parte de los neurocientíficos es la de adentrarse por terrenos que tradicionalmente han sido considerados propios de la metafísica, entre ellos los que tienen que ver con la realidad humana (vida humana, esencia, identidad, conciencia, yo, subjetividad, experiencia, dignidad, etc.), aunque utilizándolos sin las oportunas precisiones y remitiéndolos

3 Churchland, P. S., Brain-Wise, Cambridge: MIT Press, 2002. Vid., no obstante, Damasio, A., El error de Descartes. Barcelona: Crítica, 2006 y Morgado, I., Emociones e inteligencia social, $2^{a}$ edición, Barcelona: Ariel: 2010.

4 Vid., por ejemplo, ZubIRI, X., Inteligencia sentiente. Madrid: Alianza, 1980. 
exclusivamente a los procesos neuronales (por ejemplo, al «yo neural») la neurociencia tendría que aprender de la genética la lección de evitar convertirse en una metafísica ${ }^{6}$, en su caso de carácter neuronómico, y abstenerse de afirmaciones falaces como la de que «somos nuestros cerebros». Porque eso implica una especie de «neuroesencialismo», en la medida en que se pretende que son los cerebros los que definen quiénes somos ${ }^{7}$.

Este creciente movimiento neurocientífico se ha visto reforzado por las innovaciones tecnológicas que permiten una visualización de la actividad cerebral mediante la neuroimagen (neuroimaging), llegándose a creer en ocasiones que sobre esa base estamos leyendo el cerebro y comprendiendo los más recónditos entresijos de la persona humana. Sin embargo, nuestra experiencia de lo que es la vida personal no encaja fácilmente en la comprensión reducida de la misma que ofrecen hasta ahora las nuevas tecnologías para visualizar el cerebro ${ }^{8}$. Además, lo que no se puede negar es que existen dos lenguajes: el neurobiológico y el psicológico (el propio del lenguaje ordinario), cuya raíz se encuentra siempre en el mundo de la vida9. Y, por tanto, habría dos interpretaciones de tales procesos, pues a la descripción en términos neurobiológicos se añade una interpretación psicológica y humanística, más cercana a la concepción cotidiana, que incorpora la perspectiva experiencial de la subjetividad humana en primera persona.

Indudablemente hay que contar con la investigación del cerebro para comprender lo que nos hace humanos y también personas. Como la genética, la neurociencia concierne a las bases biológicas de lo que somos, de nuestra realidad humana. Incluso muchos piensan que la relación de la realidad personal con el cerebro todavía puede ser más estrecha que con el genoma. Ahora bien, lo más problemático es la interpretación de lo que se vaya logrando mediante la investigación: «el problema fundamental es cómo interpretar lo que puede ser información ambigua acerca del cerebro, que está basada sobre medidas indirectas de la estructura y función del cerebro» ${ }^{10}$, y que está cargada de valores y determinada culturalmente.

Si no se quiere caer en dogmatismos ni en un imperialismo neurocientífico, habrá que revisar las diversas concepciones del cerebro que se proponen. Por ejemplo, que «es el órgano de la individualidad», de la mente, la conciencia y

5 Damasio, A., El error de Descartes, Barcelona, Crítica, 2010, 271-280. Vid. Monserrat, J. «Teoría de la mente en Antonio R. Damasio», Pensamiento, vol. 59, no 224 (2003), 177-213.

6 Green, R.M., «From genome to brainome: charting the lessons learned», en IlLES, J. (ed.), Neuroethics. Oxford: Oxford University Press, 105-121.

7 Roskies, A., «Neuroethics for the New Millennium», en Glannon, W. (ed.), Defining Right and Wrong in Brain Science. New York: Dana Press, 2007, 12-18.

8 FARAH, M. J. and WolPE, P. R., «Monitoring and Manipulating Brain Function: New Neuroscience Technologies and Their Ethical Implications», en Glannon, W. (ed.), Defining Right and Wrong in Brain Science, 37-57.

9 Habermas, J., Entre naturalismo y religión. Barcelona: Paidós, 2006; «Die Herausforderung des Naturalismus» en Philosophische Texte. Bd. 5. Frankfurt: Suhrkamp, 2009.

10 Glannon, W. (ed.), Defining Right and Wrong in Brain Science, 33, 37 y 95. 
la mismidad ${ }^{11}$, «la sede de la mente» y la esencia del self. O bien, que el cerebro es una máquina causal, una entidad física que determina la mente, aun cuando sin impedir - curiosamente- que haya responsabilidad. Sin embargo, otros se sienten obligados a distinguir entre cerebros, mentes y personas, pues no se puede hacer responsables a los cerebros, sino que son las personas las que se han de hacer responsables de sus acciones. De ahí que haya quienes afirmen que la neurociencia nunca encontrará el correlato cerebral de la responsabilidad, porque es algo que atribuimos a las personas, no a los cerebros. Y otros incluso reconocen abiertamente que hoy en día no sabemos cómo el cerebro hace posible (enable) la mente ${ }^{12}$.

Así pues, existen diversas líneas de interpretación de los conocimientos neurocientíficos y no todas esperan desentrañar el «significado último» de las experiencias humanas a partir sólo de los circuitos neuronales que intervienen en ellas ${ }^{13}$. Hay, pues, alternativas a la línea preponderante (antes aludida), a través de ciertas formas de "neurofenomenología», por ejemplo, las de Georg Northoff $^{14}$, Francisco Varela ${ }^{15}$ y, en cierto modo, Gallagher y Zahevi ${ }^{16}$, y García Ruiz $^{17}$, quienes intentan lograr una unión de datos científicos y conceptos filosóficos, sin disolver la filosofía en las neurociencias, incorporando las tradiciones filosóficas que recuperan la vivencia subjetiva y la perspectiva de la primera persona, y advirtiendo de la necesidad metodológica de no confundir datos y hechos empíricos con conceptos filosóficos. Una distinción semejante a la que establece también Zubiri en su Noología entre el «análisis de los hechos» y los «razonamientos conceptuales» de una "teoría»" ${ }^{18}$. Precisamente la aportación zubiriana, situándose más allá de la fenomenología, constituye una auténtica alternativa en el horizonte actual, capaz de combinar el análisis filosófico con los conocimientos científicos del cerebro y, en concreto, de gran relevancia para la cuestión de la realidad personal.

A mi juicio, es necesario lograr una noción integral de realidad humana ante el creciente naturalismo y computacionismo, y esa es una de las aportaciones

11 Ibídem, 31, 76, 182-194. Le Doux, J., The emotional brain, Londres, Nueva York, Simon \& Schuster, 1996; Damasio, A., El error de Descartes. Barcelona: Crítica, 2006; Changeux, J.-P., L'homme neuronal. Paris: Fayard, 1983; Raison et plaisir. Paris: Odile Jacob, 1994; Changeux, J.-P. -Sobre lo verdadero, lo bello y el bien. Buenos Aires: Katz, 2010; Changeux, J.-P. y Ricoeur, P., Lo que nos hace pensar: la naturaleza y la regla. Barcelona: Península, 1999; Edelman, G., Neural Darwinism. Nueva York: Basic books, 1987; Bright air,brilliant fire. Nueva York: Basic books, 1992; Edelman, G. y Tononi, G., Consciousness. Londres: Penguin Books, 2000.

12 Damasio, A., El error de Descartes, 294 y Morse, S. J., «Moral and legal responsability and the new neuroscience», en ILLES, J. (ed.), Neuroethics, 33-50.

13 Cortina, A. (ed.), Guía Comares de Neurofilosofía práctica. Granada. Comares, 2012.

14 Northoff, G., Das Gehirn. Paderborn: Mentis, 2000.

15 VARela, F., «Neurophenomenology: a methodological remedy to the hard problem», Journal of Consciousness Studies 3, 330-350.

16 Gallagher, S. y Zahavi, D., La mente fenomenológica. Madrid: Alianza, 2013.

17 García Ruiz, E., «El nudo del mundo. Subjetividad y ontología de la primera persona», Eidos, 10 (2009), 194-223.

18 ZuBIRI, X., Inteligencia sentiente. Madrid: Alianza, 1980, Prólogo, 20 y pássim. 
que la filosofía de Zubiri nos puede ofrecer en el actual contexto marcado por la expansión de las neurociencias. Pues existe una indefinición e indeterminación del significado de la noción de persona. En ocasiones aparece usada de un modo acrítico e impreciso, porque, aunque da la sensación de tener ciertas resonancias filosóficas, sin embargo falta la necesaria reflexión y normalmente se desliza hacia un reduccionismo de tipo naturalista y/o computacional. Prácticamente en ningún caso se plantea la cuestión de la realidad personal. Pues, a lo sumo, se trata al hombre como un animal algo más complejo o como una máquina peculiar (hasta cuando se lo especifica como con un cerebro digital mejorable).

\section{SignificAdo DE PERSONA EN EL HORIZONTE HISTÓRICO QUE OFRECE ZUBIRI}

La filosofía zubiriana sobre la realidad personal comienza muy pronto y puede ser muy apropiada en un tiempo marcado por las neurociencias, porque también desde muy pronto incorporó en sus estudios y reflexiones la dimensión biológica, no sólo de la genética sino también de la neurología. Ya en los artículos y trabajos que Zubiri elaboró en los años treinta se encuentra el arranque de su concepción de la persona ${ }^{19}$. En ellos cabe descubrir varias fuentes de inspiración: tanto la tradición filosófica y teológica como los crecientes conocimientos científicos.

La filosofía occidental nació apoyada en la naturaleza y de ahí que comprendiera al hombre formando parte de ella. Pero fue un fracaso, un «vano intento», el «naturalizar al logos y al hombre»; y sería un error entenderlo como un ser puramente natural. La innovación del cristianismo al descubrir un mundo espiritual y personal que trasciende la naturaleza amplió la experiencia vital y cambió el horizonte del filosofar ${ }^{20}$. La experiencia religiosa se convirtió así en un principio de innovación para la razón filosófica. Ciertamente, toda filosofía tiene a su base, como supuesto suyo, una cierta experiencia, y toda experiencia surge gracias a una situación y supone un horizonte ${ }^{21}$.

Para comprender la revelación había que superar el horizonte naturalista de la filosofía griega y una de las nuevas adquisiciones fue la noción de persona. Ésta no se identificaba con «naturaleza» (physis) sino que se expresaba mediante el término hipóstasis (hypóstasis); ya los teólogos escolásticos decían que no son lo mismo naturaleza y persona, sino que ambos momentos se hallan entre sí en la relación de «aquello por lo que se es» (natura ut quo) y «aquel que se es» (suppositum ut quod). Pero, además, todavía habría que despojar

19 «Sobre el problema de la filosofía» (1933); «En torno al problema de Dios» (1935); «¿Qué es psicología?» (1935); «Res cogitans» (1937), recogidos en ZuBIRI, X., Sobre el problema de la filosofía y otros escritos (1932-1944). Madrid: Alianza, 2002, con Presentación de Germán Marquínez Argote.

20 Zubiri, X., Naturaleza, Historia, Dios. Madrid: Alianza, 1987, 9ª edición, 55.

21 Ibídem, 193. 
de su sentido inicial a la palabra hypóstasis, que significaba un hypokeímenon, un subjectum, una sustancia), para que pudiera expresar la experiencia vivida a partir del ámbito de la revelación religiosa y «traducir» lo que los latinos llamaron «persona» en el sentido jurídico de la palabra, a diferencia de «res» $»^{22}$.

Un camino para superar las limitaciones de la metafísica griega y llenar la falta de un concepto de "persona» fue San Agustín, a cuyos textos remite Zubiri para mostrar la diferencia entre la persona y la naturaleza ${ }^{23}$ : «Pero, cuando estas potencias se encuentran en una persona como es el hombre, pudiera alguien decirnos: estas tres potencias, memoria, entendimiento y amor son mías, no suyas; y lo que obran no lo obran para sí, sino en mi favor o mejor dicho, soy yo el que por medio de ellas actúo. Recuerdo por mi memoria, comprendo con mi inteligencia, amo con mi voluntad (...) Yo recuerdo, entiendo y amo sirviéndome de mis tres facultades, aunque no soy mi memoria, ni mi entendimiento, ni mi amor; mas poseo estas tres realidades ${ }^{24}$.

Zubiri se apoya de nuevo en este texto años más tarde (en el curso Sobre la realidad de 1966) para determinar qué es ser persona, diferenciándola de la naturaleza y de las facultades que posee el sujeto personal, que no se puede entender adecuadamente, si sólo se lo contempla desde el punto de vista de los actos, porque entonces «no se ha tocado el problema de la persona». $\mathrm{Ni}$ los predicados ni los actos de la persona son los que constituyen la estructura de la persona como tal. «La inteligencia y la voluntad no son capaces de constituir una persona más que en la medida en que constituyen previamente ese momento del mío, del mí, de quien es la inteligencia y la voluntad $»^{25}$. Y comentando el texto de San Agustín resalta Zubiri dos aspectos: 1) la diferencia entre lo poseído y el posidente, es decir, entre lo que tengo (el conjunto de las facultades, cuya unidad es lo que se ha llamado «naturaleza») y lo que soy, la persona; y 2) la caracterización del posidente de esas facultades naturales como un ego, como un yo, relacionando esta segunda perspectiva con la vida personal, de manera que ser persona consistiría aquí en ser un yo.

Sin embargo, Zubiri no se conformará con esta respuesta a la pregunta acerca de en qué consiste realmente la diferencia entre naturaleza y persona, sino que considera ineludible pensar sobre qué es ese sujeto posidente respecto de la naturaleza que posee, pues, por una parte, hay que preguntar a) si es un sujeto vacío de naturaleza y carente de toda determinación; pero, por otra, b) si el sujeto está dotado de ciertas estructuras naturales y entonces desaparecería la

22 ZuBuri, X., Sobre el problema de la filosofía y otros escritos, 90-91; El hombre y Dios, Nueva edición. Madrid: Alianza, 2012, 542. Vid. también Gracia, D., «Persona y comunidad. De Boecio a Tomás de Aquino», Cuadernos Salmantinos de Filosofía, 11 (1984), 63-106; «La historia como problema metafísico», Realitas III-IV, 1979, 79-149.

${ }_{23}$ ZUBIRI, X., Sobre el problema de la filosofía, 222, nota 3.

24 SAn Agustín, Obras completas. Madrid: BAC, 1985, vol. V, 22, 42 (De Trin. Lib. XV, c. 22).

25 Zubiri, X., Sobre la realidad, Madrid, Alianza, 2001, con Presentación de José A. Martínez, 205-206. 
persona. La respuesta de Zubiri dice así: «Si por el primer lado desaparece porque el sujeto queda vaciado de naturaleza, en el segundo desaparece absorbido por ella. En definitiva, la presunta diferencia entre naturaleza y persona se nos ha ido de las manos» ${ }^{26}$.

Esta reflexión lleva a Zubiri a cuestionarse, en un paso ulterior, si es adecuado pensar que «ser persona consiste en ser sujeto de atribución de sus actos y de sus notas», es decir, hay que preguntarse si el hecho de que el hombre sea en alguna medida «sujeto de sus actos» es «lo que hace que el hombre sea una persona».

La respuesta de Zubiri es decisiva para comprender la concepción de la persona que va a mantener en su metafísica posterior, en la que distingue entre el orden talitativo y el transcendental. En el orden de la talidad, el hombre es considerado como un sujeto que ejecuta actos y recibe afecciones -impresiones- del mundo a través de sus sentidos. Pero, si se toma esa talidad «en función transcendental», el sujeto es persona por ser suyo, no por ser sujeto. El ser sujeto depende del orden talitativo, pero el ser persona consiste no en ser sujeto sino en ser suyo en tanto que realidad, en pertenecerse a sí mismo. La persona consiste en una forma de realidad que es suya. La esencia metafísica de la persona en cuanto tal no viene determinada por el orden de la talidad, sino que, para Zubiri, persona es «el carácter transcendental de la esencia abierta», que «es suya, formal y reduplicativamente suya, en tanto que realidad ${ }^{27}$.

\section{LA PERSONA EN EL ANÁLISIS ONTOLÓGICO DE LA EXISTENCIA}

En el contexto de su artículo «En torno al problema de Dios» (1935) ${ }^{28}$, Zubiri propone mejorar el análisis de la existencia que encontró en la Analítica existencial heideggeriana, a la que alude con las expresiones «se nos dice» $\mathrm{y}$ «se nos dice hoy». Precisamente uno de los elementos más relevantes de esa mejora analítico-existencial consiste en introducir la noción de persona: «el hombre existe ya como persona ${ }^{29}$, situando la cuestión radical de la persona en la dimensión ontológica. La persona es el ser del hombre y se encuentra «implantada» en el ser para realizarse mediante la complejidad del vivir. El hombre, pues, existe como persona y tiene que realizarse en su vida como persona. No es un mero «factum» ( la presunta facticidad de la existencia es sólo una denominación provisional») ${ }^{30}$, sino -como decía ya Ortega y Gasset- un «faciendum».

\footnotetext{
26 Ibídem, 208.

27 Ibídem, 209.

28 ZuBiri, X., Sobre el problema de la filosofía y otros escritos, 215-241; Naturaleza, Historia, Dios, 417-454.

29 Zubiri, X., Sobre el problema de la filosofía y otros escritos, 223; Naturaleza, Historia, Dios, 427.

30 Zubiri, X., Sobre el problema de la filosofía y otros escritos, 224; Naturaleza, Historia, Dios, 427.
} 
En conexión con esta incorporación de la noción de persona en el análisis existencial de carácter ontológico Zubiri destaca algunos aspectos ligados con ella. Primero, que el hombre no es su existencia, sino que la existencia es suya. El hombre es este "ser suyo", por cuanto su vida está en cierto modo en sus manos. El hombre asiste al transcurso de su vida, pero su persona «es» allende este pasar. Por eso el hombre puede modificar su vida, por ejemplo, puede «arrepentirse» y convertirse en otro, puede «perdonar» al prójimo. Estos «fenómenos» del arrepentimiento y del perdón, según Zubiri, son personales, es decir, no se refieren a la vida que pasa, sino a la persona, que es lo que le queda al hombre de "suyo»; la vida pasa, la persona queda. Así pues, el hombre, además de tener vida, es persona.

En su análisis mejorado de la existencia Zubiri destaca, además de la diferencia entre existencia y persona, los fenómenos de la apertura y la religación. Existir es vivir, pero el hombre no es su vida, sino que «vive para ser» [persona] y su ser [persona] está allende su existencia en el sentido de «vida». Hay, pues, una trascendencia del ser del hombre respecto de su propia vida, que permite que la persona pueda volverse contra la vida misma. Y esto, que es lo que «nos hace libres», supone, según Zubiri, una dimensión más profunda e innovadora en su análisis existencial-ontológico de los años treinta, que denomina «religación». La existencia humana no está solamente «arrojada» entre las cosas, sino «religada» por su raíz; la religación es una dimensión constitutiva de la existencia y el supuesto más radical del hombre, sin el que no es posible volverse contra sí mismo, como ocurre en los fenómenos personales del arrepentimiento y el perdón, o incluso cuando se va en contra de la vida misma. Por estar religado como persona, el hombre es un sujeto «absoluto» (aunque relativo por ser «cobrado»), suelto de su propia vida, pero «suyo»; implantado en la existencia religadamente, pero haciéndose, como algo suyo. El hombre, además de estar abierto a las cosas, está abierto por la religación a la raíz fundamental de la existencia, a lo que religa y apoya haciéndole ser, al fundamento. Se trata de la apertura al orden de la fundamentalidad de la existencia en virtud de la religación ${ }^{31}$. «En la apertura que es la religación, el hombre está puesto en la existencia, implantado en el ser (...) como viniendo "desde" ${ }^{32}$. Porque la libertad sólo es posible como religación, es decir, "no hay "libertad" sin "fundamento" ${ }^{33}$. Se trata de la dimensión más profunda del análisis existencial de carácter ontológico que ofrece Zubiri en los años treinta.

Pero no deben pasar desapercibidas ciertas diferencias entre la versión de 1935, publicada en Revista de Occidente, y la versión corregida y ampliada de

31 A la enumeración de «proposiciones» que ofrece la versión publicada en Revista de Occidente en 1935 la posterior de Naturaleza, Historia, Dios añade varios números más (del 9 al 11), en los que incorpora la perspectiva de la fundamentalidad de la existencia humana a partir de la religación.

32 Zubiri, X., Naturaleza, Historia, Dios, 433.

33 Zubiri, X., Sobre el problema de la filosofía y otros escritos, 234; Naturaleza, Historia, Dios, 446. 
«En torno al problema de Dios», de 1936 en Roma. En esta última Zubiri añade varios párrafos, en los que resalta de manera especial la perspectiva de la fundamentalidad de la existencia a partir de la religación (antes expuesta) y en la que se encuentra algún texto como el siguiente, que resulta muy significativo para el tema crucial de la relación entre naturaleza y persona: «La religación no es una dimensión que pertenezca a la naturaleza del hombre, sino a su persona, si se quiere a su naturaleza personalizada. La pura naturaleza con el simple mecanismo de sus facultades anímicas y psicofísicas no es el sujeto formal de la religación. El sujeto formal de la religación es la naturaleza personalizada. Estamos religados primariamente no en cuanto dotados naturalmente de ciertas propiedades, sino en cuanto subsistentes personalmente» ${ }^{34}$.

\section{LA PERSONA DESDE LA PERSPECTIVA NEUROCIENTÍFICA EN ZUBIRI}

Zubiri ha sido un pensador muy atento desde siempre al conocimiento científico y ha tenido una elevadísima valoración de la ciencia moderna. Recordemos que coloca a la ciencia moderna junto a los otros tres productos más gigantescos del espíritu humano (metafísica griega, derecho romano y religión de Israel), equiparándola en grandeza a aquellos tres legados ${ }^{35}$.

El ambiente intelectual en que se movió Zubiri, sobre todo el orteguiano, era propicio a tal actitud en relación con las ciencias en general y la neurociencia en particular. Valga como ejemplo, el hecho de que el propio Ortega y Gasset colaboró en la creación de la revista «Archivos de Neurobiología», formó parte de su dirección y redactó el texto principal de su presentación (fechada en marzo de 1920$)^{36}$. Era una expresión del movimiento científico que se vivía en España y del progreso que estaban alcanzando los estudios neurológicos, en concreto en histología y fisiología del sistema nervioso, por parte de Santiago Ramón y Cajal ${ }^{37}$ y Luis Simarro ${ }^{38}$.

La conexión entre filosofía y ciencia se encuentra en Zubiri desde un principio hasta su trilogía sobre Inteligencia sentiente. Recuérdese que en su pensamiento la perspectiva psicofísica que incorpora la dimensión natural del cuerpo humano en la "persona corporal» o en el «cuerpo personal» se remonta a los años treinta, en concreto se encuentra explícita en los estudios titulados «¿Qué es Psicología?» (1935) y «Res cogitans» (1937) ${ }^{39}$, cuyo desarrollo se encuentra en los años cuarenta y cincuenta (véase Sobre el hombre), y posteriormente en los artículos «El hombre, realidad personal» (1963), «El origen del

34 Zubiri, X., Naturaleza, Historia, Dios, 430.

35 Ibídem, 27-57.

36 Ortega y Gasset, J., Obras completas. Madrid: Taurus, 2005, vol. III, 324 y 926.

37 Laín Entralgo, P., Escritos sobre Cajal. Madrid: Triacastela, 2008.

38 CArpintero, H., Luis Simarro. Valencia. PUV, 2014.

39 Recogidos en Zubiri, X., Sobre el problema de la filosofía y otros escritos (1932-1944). Madrid: Alianza, 2002, con Presentación de Germán Marquínez Argote. 
hombre» (1964), «Notas sobre la inteligencia humana» (1967-68) , $^{40}$ «El hombre y su cuerpo» (1973), en algunos estudios recogidos en Sobre el sentimiento y la volición; y de modo muy especial en algunos trabajos pioneros sobre la «Actividad cerebral y la actividad intelectiva y opcional», recogidos en Sobre el hombre y que han servido de base al intento de fundamentar biológicamente la moral por parte de Ignacio Ellacuría en «Biología e inteligencia» (1977) y «Fundamentación biológica de la ética» $(1979)^{41}$. Este intento de fundamentación estaba conectado también con los trabajos sobre "Antropología médica» de Pedro Laín Entralgo y de Diego Gracia, luego proseguidos en el caso de Pedro Laín por una teoría del cuerpo humano y, en el caso de Diego Gracia, por sus estudios de bioética. Y sin olvidar que esta línea zubiriana de fundamentación de la moral tuvo en la Ética (1958) de José Luis López Aranguren su primer desarrollo y exposición.

\subsection{Conciencia y persona: ¿la realidad personal en la Psicología fisiológica?}

En «¿Qué es psicología?»(1935), al hilo de los Principios de la Psicología fisiológica de Wundt, Zubiri plantea la cuestión del estudio de la conciencia mediante los métodos experimentales de la fisiología. La Psicología, como ciencia experimental, debe considerar el psiquismo humano desde el punto de vista natural.

En este contexto científico Zubiri resalta un punto central a partir de Wundt: si bien hasta entonces «se creía que existían dos experiencias, la externa y la interna», la nueva metodología de las ciencias experimentales, aplicada al psiquismo humano, homogeneiza las experiencias y los fenómenos psíquicos haciéndolos equivalentes. Y su única posible diferenciación «depende del punto de vista que se tome»: «de que me afecte a mí o se encuentre incurso en el curso de mi conciencia» ${ }^{42}$.

Desde la perspectiva filosófica, la cuestión básica es la que concierne al carácter de la experiencia de los fenómenos de conciencia: «¿Existen o no fenómenos de conciencia?», ¿ es la conciencia humana un trozo de la naturaleza y del Universo? La respuesta filosófica de Zubiri se centra aquí en «el gran error del positivismo»: «haber tratado de definir el carácter del objeto de una ciencia por el método que esta emplea», pero los métodos han de fundarse en el carácter del objeto. Y éste es un problema filosófico y la pregunta radical dice así: «¿Existe, puede existir el hombre como pósito de una ciencia?». La respuesta de la filosofía moderna es que «la conciencia no es un pósito, no es una parte de la naturaleza y por eso no puede ser objeto de una ciencia natural» ${ }^{43}$. Sin

40 Vid. el iluminador trabajo de CARPINTERo, H., «Xavier Zubiri y la doctrina de la inteligencia sentiente», revista Exilio, Invierno-Primavera, 1972-73, 61-78.

41 Vid. Conill, J., «Las líneas de fundamentación en la propuesta ética de Ellacuría», en Ignacio Ellacuría 20 años después. Sevilla: Junta de Andalucía, 2010, 81-92.

42 Zubiri, X., Sobre el problema de la filosofía y otros escritos, 247-248.

43 Ibídem, 249. 
negarle al hombre su «existencia natural», lo esencial es su ser «persona», lo cual significa que «trasciende la Naturaleza» y es irreductible a ella. La conciencia no es un trozo de la «physis», con lo cual se produce una «desnaturalización de la conciencia», y Zubiri remite en este contexto a Heidegger. Pero, a continuación, Zubiri plantea la necesidad de superar esta herencia del «idealismo trascendental», expresada en el carácter "transfísico de la persona humana», preguntando más bien «por qué el espíritu humano [la persona] por y para ser trascendental [transfísico] es natural? ${ }^{44}$. Con lo cual queda claro que, en el contexto científico de las nuevas ciencias de la época, como la Psicología Fisiológica, Zubiri plantea la cuestión filosófica de la relación entre naturaleza y persona en términos que están más allá del idealismo y del positivismo.

El problema filosófico consiste en saber si la persona es un "hecho natural». Pero, aunque no sea así, a Zubiri no le parece suficiente comprender la dimensión personal mediante la noción tradicional de substancia, ni tampoco con la de conciencia (como ha sido preponderante en la época moderna), ni acepta situar la cuestión de la persona en relación con el problema cuerpo-alma, sino que más bien hay que separar ambos asuntos, ya que cuerpo y alma suelen entenderse como dos «res» (en sentido cartesiano), pero la persona es algo distinto $^{45}$.

De lo que se trata en el problema de la persona, no es ni de fundar la dimensión personal en la natural, ni tampoco de yuxtaponer ambas dimensiones, sino «de hacer ver que el espíritu, si tiene cuerpo o natura, no lo tiene extrínsecamente sino que, por el contrario, la persona (...) tiene una natura porque le es indispensable», es decir, mostrar cómo la persona es «trascendentalmente natural». Lo cual implica entrar en un asunto cada vez más difícil en la filosofía contemporánea: qué significa «trascendental» (más allá del sentido medieval y del habitual sentido kantiano ${ }^{46}$.

Zubiri remite en este contexto a «la gran innovación de Heidegger», que consiste precisamente en haber visto que la «trascendentalidad de la existencia es un carácter constitutivo del hombre», en haber situado lo trascendental en la existencia humana, mostrándola como existencia trascendental. Por mi parte, creo que habría que interpretar este giro en la concepción de lo trascendental, resaltando que se trata de situarlo en el orden de la facticidad. La interpretación que lleva a cabo Zubiri de esa existencia trascendental (a mi juicio, de esa facticidad trascendental) se distancia tanto de la «interpretación sustancial de la existencia humana» como de la heideggeriana, preguntándose por el carácter de «cadaunidad» e individualidad de dicha existencia trascendental, lo cual le conduce al problema — que considera «metafísico»— de la intimidad de cada persona y al problema de la corporeidad ${ }^{47}$.

44 Ibidem, 254.

45 Ibídem, 257 y 258.

46 Ibídem, 259.

47 Ibídem, 261. 


\subsection{Cuerpo y persona}

Por tanto, hay que preguntarse qué es eso del cuerpo, porque hay diversos conceptos de cuerpo. Es éste un tema crucial en la filosofía contemporánea, en particular desde Nietzsche ${ }^{48}$, tratado ya por Ortega y Gasset de modo muy significativo $^{49}$, y de gran trascendencia también en el desarrollo de la propia filosofía zubiriana, especialmente por parte de Laín Entralgo ${ }^{50}$. Tanto para Ortega y Gasset como para Zubiri, no es igual mi cuerpo que el de los otros. El momento del «mi» pertenece a mi cuerpo, por tanto, «el sentido de la corporeidad es radicalmente distinto de la corporeidad física ${ }^{51}$. Por eso Zubiri considera que lo decisivo del problema del cuerpo es que se trata de «mi cuerpo», lo cual arranca «de aquel de quien es el cuerpo, es decir, del espíritu trascendental», de la «interioridad personal».

A lo que conduce esta reflexión zubiriana sobre el cuerpo como "principio de finitud existencial» es a mostrar que «el sentido del cuerpo humano» es igual al «sentido de la naturaleza trascendental del hombre» y a plantear «el problema del sentido corpóreo del espíritu humano». Su vía de respuesta a la pregunta acerca de qué es el cuerpo humano, ya en este contexto, es empezar recurriendo a la Fisiología, aunque advirtiendo que el «acontecer biológico del hombre (...) no agota el sentido trascendental ni siquiera el biológico del hombre ${ }^{52}$. Pues «el ente trascendental que es la persona humana nos aparece como ente natural», porque, a diferencia de las demás cosas, el hombre es «un ente naturalizado que emerge de la naturaleza para ser lo que es»; tiene una naturaleza no sólo naturata, sino también naturans ( "natura seipsum naturans»).

Será justamente en «Res cogitans» (1937) donde Zubiri prosiga su reflexión sobre la persona y el cuerpo, tanto a partir de la historia del pensamiento como de las aportaciones científicas sobre la naturaleza humana. Insiste una vez más en la deficiencia de la metafísica griega y en la aportación de San Agustín con su concepto de espíritu. Y sitúa el problema de lo «específicamente humano del hombre» no en "los caracteres o cualidades que el hombre posee a diferencia de las otras cosas, sino en la manera como él forma parte del mundo» ${ }^{53}$. Porque, además de todo lo que tiene, «el hombre existe para sí mismo»y «determina su propio ser»; y eso lo expresamos diciendo que «el hombre es persona»:

48 Vid. Conill, J., El poder de la mentira. Nietzsche y la política de la transvaloración. Madrid: Tecnos, 1997, Prólogo de Pedro Laín Entralgo.

49 Vid., por ejemplo, Ortega y Gasset, J., Meditaciones del Quijote (1914), Obras completas, vol. I, 2004, 825 y «Sobre la expresión, fenómeno cósmico» (1925), Obras completas, Taurus, II, 680-695; Conill, J., «Una cierta lectura hermenéutica de la filosofía orteguiana», en Zamora, J. (ed.), Guía Comares de Ortega y Gasset. Granada: Comares, 2013, 207-227.

50 Vid. Laín Entralgo, P., El cuerpo humano. Madrid: Espasa-Calpe, 1989; Cuerpo y alma, Madrid, Espasa-Calpe, 1991; Alma, cuerpo, persona. Barcelona: Galaxia Gutenberg/Círculo de Lectores, 1995.

51 ZuBIRI, X., Sobre el problema de la filosofía y otros escritos, 262.

52 Ibídem, p. 263.

53 Ibidem, p. 295. 
«Una persona es aquello que se determina a ser de una manera o de otra y, por consiguiente, es aquello que se determina en el ser ${ }^{54}$. Y, aunque toda determinación se resuelve entre posibilidades concretas de ser en la vida histórica, ni la vida ni la historia son el ser del hombre. Pues lo que «soy» como persona determinada es lo que en mi vida e historia «me pertenece», porque «no todo lo que pasa en mí o conmigo es mío» ${ }^{55}$.

Es, pues, conveniente dejar claro que para comprender el cuerpo humano no basta estudiar las facultades psicofísicas del hombre, su «naturaleza», porque el cuerpo humano no es un cuerpo como lo es un cuerpo físico, sino que «en su realidad concreta es (...) la encarnación de una persona». Por eso Zubiri llega a afirmar lo siguiente: "yo soy el cuerpo», "yo soy un cuerpo personal», "yo soy una persona corporal» ${ }^{56}$.

El cuerpo humano no puede comprenderse sólo a partir del mecanismo de sus facultades, porque la "naturaleza humana», en lo que tiene de «físico», es meramente una natura naturata. Por tanto, no se ha de confundir ni identificar con la persona humana, y por eso Zubiri afirma tajantemente que «la cuestión del ser del hombre jamás podrá ser resuelta por vía naturalista, porque el hombre existe personalmente». Y aclara en nota que había desarrollado "esta interpretación» en dos conferencias dadas en la Universidad de Barcelona, en 1935, con el título «¿Qué es Psicología?» ${ }^{57}$.

\subsection{Inteligencia y persona: la persona se funda en la inteligencia}

Hemos visto que ya en los años treinta Zubiri pasa del estudio de la conciencia en la Psicología fisiológica a la corporeidad y en los cuarenta a la inteligencia, por eso me parece que la naturalización de la conciencia, tanto entonces como ahora por su renovada actualidad en las neurociencias ${ }^{58}$, no toca el punto central de la posición zubiriana, que se va a concretar en una nueva concepción de la inteligencia, la cual, aun cuando está basada en el desarrollo del cerebro, sin embargo, no puede ser explicada exclusivamente por vía naturalista, sino que responde a una cuestión más fundamental y es la del puesto del hombre en la naturaleza, en el mundo y en la realidad ${ }^{59}$. A ello contribuyen los estudios de la Antropobiología de la primera parte del siglo xx (Scheler, Gehlen, Plessner, Uexküll, Portmann, Buytendijk), cuyas aportaciones biológicas y las neurológicas ofrecen una base a la innovadora interpretación zubiriana de la

54 Ibidem, p. 295.

55 Ibidem, p. 298.

56 Ibidem, pp. 297 y 298.

57 Ibidem, p. 298, nota 4.

58 Vid., por ejemplo, CRICK, F., La búsqueda científica del alma. Madrid: Debate, 1994; Edelman, G.M. y Tononi, G., El universo de la conciencia. Barcelona: Crítica, 2002; MonsERRAT, J., "Gerald M. Edelman y su antropología neurológica», Pensamiento, vol. 62, n 234 (2006), 441-470; Morgado, I., Cómo percibimos el mundo. Barcelona: Ariel, 2012.

59 Vid. Gracia, D., "El puesto del hombre en la realidad», Cuadernos Salmantinos de Filosofía, 40 (2013), 611-643. 
inteligencia sentiente ${ }^{60}$, según la cual «todo lo biológico es mental, y todo lo mental es biológico» ${ }^{61}$. Esta concepción de la inteligencia se sustenta en una nueva formalización ejercida por el cerebro humano, que Zubiri denomina «hiperformalización» y que es la que permite actualizar las cosas en una nueva formalidad, la formalidad de realidad.

Esta línea de investigación es la que Zubiri va desarrollando en los años cuarenta y cincuenta, exponiéndola en los cursos de esos años, así como en «El problema del hombre» (1959), «El hombre, realidad personal» (1963) y «Notas sobre la inteligencia humana»(1966-67). La inteligencia es la que permite que el hombre esté abierto al mundo, que sea una «esencia abierta» y una «sustantividad» (con independencia del medio y control específico sobre él). Contando con el arsenal de los conocimientos biológicos y los neurológicos de la época (años cuarenta y cincuenta), Zubiri va perfilando su nueva concepción de la inteligencia y llega en su filosofía a comprender al hombre como «animal de realidades» $\mathrm{y}$ «animal personal».

Diego Gracia cita el contexto de la lección 29 del curso sobre la libertad, fechada el 5 de mayo de $1952^{62}$, en el que Zubiri expone que la «versión a la realidad» a que nos abre la inteligencia surge por «emergencia» desde las estructuras biológicas del ser humano y que el órgano que ejerce esa innovadora función formalizadora como hiperformalización es el cerebro. Así pues, la primera función de la inteligencia es biológica. Zubiri cuenta con los conocimientos que aportan las ciencias y, a partir de estos conocimientos científicos (biológicos y neurológicos), reelabora su filosofía, que conducirá a desarrollar una metafísica de la realidad personal y una noología de la intelección sentiente.

Ya en «El problema del hombre» ${ }^{63}$ expone Zubiri los dos aspectos decisivos para comprender la realidad humana como una sustantividad con inteligencia sentiente, capaz de fundar lo que es la persona, es decir, muestra que la «inteligencia sentiente» que hace del hombre un «animal de realidades» hace de él asimismo [eo ipso] un «animal personal».

¿Por qué el animal de realidades tiene sustantividad personal? La respuesta se encuentra en la inteligencia, la nota estructural que consiste en la capacidad de enfrentarse con las cosas como realidad. En definitiva, desde el punto de vista constitutivo, la persona se funda en la inteligencia, como estructura que garantiza y constituye la sustantividad humana ${ }^{64}$. Por tanto, la inteligencia sen-

60 Vid. Grande Covián, F., «Zubiri y la biología teórica» y RoF CARBallo, J., «Zubiri biólogo», en Homenaje a Xavier Zubiri. Madrid: Alcalá, 1953, 89-101 y 209-225, respectivamente (citados por Diego Gracia, en «El puesto del hombre en la realidad», nota 49) vid. también Rof Carballo, J., Cerebro interno y mundo emocional. Barcelona: Labor, 1952.

61 Zubiri, X., Escritos menores (1953-1983). Madrid: Alianza, 2006, con Presentación de Germán Marquínez y Fideligno Niño, 53.

62 Archivo ZubiRI, 058 BIS, 06, fol. 1537 y ss. (citados por Diego Gracia en «El puesto del hombre en la realidad»).

63 Fragmento de la lección 10 del curso «El problema del hombre», impartida el 14 de enero de 1954, en Zubiri, X., Escritos menores (1953-83). Madrid: Alianza, 2006, 31-38.

64 ZuBiri, X., Escritos menores, 35 y 38. 
tiente, según Zubiri, es la que hace al hombre animal de realidades y animal personal.

La noción de persona que Zubiri pone en juego aquí (una lección de1959, en la que remite a lo expuesto en sus cursos desde 1945) ${ }^{65}$ surge de sus estudios sobre la contraposición de la realidad del hombre con la del animal, pero partiendo de lo que les es común: el hecho de ser seres vivos. La índole esencial de todo ser vivo es la sustantividad biológica del viviente y lo decisivo para diferenciar al hombre del animal no humano está en la «formalidad», es decir, en el modo como las cosas quedan o se actualizan respecto del viviente y que Zubiri correlaciona con diferentes «habitudes». La habitud es una "emergencia» del viviente que está dotado de unas estructuras que constituyen su realidad. Zubiri llega a esas habitudes y a las estructuras a partir de las acciones.

Para determinar la habitud radical del hombre, Zubiri parte del estudio del «fenómeno del sentir», de la sensibilidad y del psiquismo animal, en el que distingue entre, por una parte, los receptores y efectores, y, por otra, la función de formalización (que es la que hace posible el incremento de la unidad formal de las estimulaciones). La clave para distinguir al hombre del animal se encuentra en la formalización, cuya función "pende de estructuras nerviosas» y es «fisiológica» ${ }^{66}$.

La función esencial del cerebro consiste en esa formalización por la que se crean las diversas situaciones a las que el animal tiene que responder ${ }^{67}$. Pero, en el caso del hombre, su cerebro se encuentra «hiperformalizado», de manera que el elenco de sus posibles respuestas no está asegurado sino que queda indeterminado. Por ser un animal hiperformalizado, una sustantividad «hiperanimal», el hombre se abre a una función distinta del sentir, la de habérselas con las cosas como realidades, que es lo que constituye la inteligencia: la capacidad de aprehender las cosas como realidades. La primera función de esta habitud intelectiva es biológica, pero esa misma función nos deja situados en la realidad, sea cual sea su contenido, con lo cual la vida del hombre queda abierta (no enclasada como la animal).

En esta habitud intelectiva hay que considerar al menos dos aspectos muy importantes. Primero, las funciones del cerebro. Pues, aunque «el cerebro no intelige», sí es «el órgano que coloca al hombre en situación de tener que inteligir

65 ZuBIRI, X., «El hombre, realidad personal», en Escritos menores, 39-63. Fragmento de la $1^{\mathrm{a}}$ lección del ciclo Cuatro lecciones sobre la persona, el 16 de abril de 1959. En esta lección dice Zubiri que presenta conceptos que ha expuesto en sus cursos desde 1945 (cfr. p. 381, nota 2).

${ }_{66}$ Ibídem, p. 49.

67 Los editores de Escritos menores remiten en una nota (en p. 381, referida al texto de p. 51) al libro de Luis Barraquer Bordas, Neurología fundamental. Barcelona: Toray, $3^{\mathrm{a}}$ ed., 1976, pp. 625-635, en el que se expone la concepción zubiriana del cerebro. Vid. también la obra posterior de Lluís Barraquer Bordas, El sistema nervioso como un todo. La persona y su enfermedad. Barcelona: Fundació Vidal i Barraquer y Paidós, 1995, con Prólogo de Federico Mayor, en que se expone el estructurismo unicista de Zubiri (desarrollado por P. Laín, I. Ellacuría y D. Gracia) como base para comprender la realidad de la persona humana. 
para poder perdurar biológicamente», para mantenerse en vilo y para perfilar el tipo de intelección. Segundo, la afirmación básica de la unidad estructural entre cerebro e intelección, entre sensibilidad e inteligencia, porque, según Zubiri, «en el hombre, todo lo biológico es mental, y todo lo mental es biológico» ${ }^{68}$.

Este resultado del análisis diferencial entre el animal y el hombre, desde el punto de vista de las habitudes, conduce a Zubiri a plantear el tema de la «unidad estructural» de la sustantividad humana, por la que la actividad intelectiva es nueva. "Contra lo que los neurólogos suelen pensar», "el psiquismo no se adscribe exclusivamente al cerebro ni tan siquiera al sistema nervioso»; «no se trata de que en el sistema nervioso acontezcan unos fenómenos puramente biológicos o bioquímicos, y que, al llegar a no se sabe qué regiones "superiores" del cerebro, surja esa especie de apéndice que sería, por ejemplo, la percepción ${ }^{69}$. A juicio de Zubiri, «esto es quimérico», pues se entendería lo psíquico como un mero epifenómeno. Como atinadamente señala Ellacuría, que la compleción de un proceso psico-neural tenga su último eslabón en el cerebro «no significa que sea en el cerebro donde la sensación se produce. La sensación no se produce donde termina el proceso, sino cuando termina el proceso ${ }^{70}$.

Hace falta otra perspectiva neurocientífica, en la que se comprenda que la función de sentir es un proceso psico-neuronal que envuelve todas las funciones y estructuras bioquímicas y biofísicas del organismo, y que no va adscrita en especial a ninguna de ellas, como no sea en sentido «diferencial». El sistema nervioso no crea la función de sentir, sino que la autonomiza, la desgaja, por diferenciación. De ahí que la función de sentir, en su aspecto psíquico, sea coextensiva a la totalidad de estructuras y procesos biológicos ${ }^{71}$.

\section{REALIDAD HUMANA COMO REALIDAD PERSONAL POR LA INTELIGENCIA}

\subsection{Análisis biológico y filosófico de la impresión ${ }^{72}$}

El análisis de la impresión, tanto desde la perspectiva filosófica como desde la biológica es decisivo para la concepción zubiriana de la inteligencia

68 ZuBIRI, X., Escritos menores, 53. Esta idea recorre toda su obra: vid. también Inteligencia sentiente. Madrid: Alianza, 1980; Sobre el hombre. Madrid: Alianza, 1986, con Presentación de Ignacio Ellacuría; El hombre y Dios. Nueva edición. Madrid: Alianza, 2012, con Presentación de Esteban Vargas; asimismo Ignacio Ellacuría, "Biología e inteligencia», Realitas III, 1979, 281-335.

69 ZuBIRI, X., Escritos menores, 59

70 Ellacuría, I., «Biología e inteligencia», en Realitas III, 1979, 331.

71 Ibídem, 60. Vid. RovaletTi, M., "La génesis primordial el psiquismo: emergencia y formalización», VERTEX, Revista Argentina de Psiquiatría, 2005, vol. XVI, 371-380; «Morfogénesis, formalización y psico(patología)», en Nicolás, J.A. y BARroso, O., (eds.), Balance y perspectivas de la filosofía de X. Zubiri. Granada: Comares, 2004, 529-552.

72 ZuBIRI, X., "Notas sobre la inteligencia humana», Asclepio, 1967-68, 341-53 (en Siete ensayos de Antropología Filosófica, editado por Germán Marquínez. Bogotá: USTA, 1982, 101-115). 
sentiente. La impresión en la sensibilidad humana tiene dos momentos: el del contenido y el de la realidad. Éste segundo momento es el de la formalidad, es decir, el modo como el contenido sensorial se nos presenta en la impresión, y que depende de la estructura de formalización del cerebro.

Este análisis de la sensibilidad humana es crucial, tanto desde el punto de vista biológico como filosófico. Desde el biológico, los procesos en la sensibilidad humana rebasan la mera estimulación, debido a la hiperformalización del cerebro humano, porque la inteligencia sentiente es la inteligencia de un animal hiperformalizado, cuyo acto psico-biológico de aprehensión consiste en hacerse cargo de la realidad (biología de la inteligencia). Y, desde el punto de vista filosófico, hay aquí un aspecto de gran relieve en relación con la fenomenología, pues, según Zuibiri, el momento de realidad de la impresión permite aclarar y determinar más adecuadamente lo que los fenomenólogos venían considerando un mero «residuo» en el análisis de la sensibilidad ${ }^{73}$. He aquí una fenomenología de la inteligencia, que se convierte en noología: análisis de la facticidad de sentir intelectivo ${ }^{74}$.

Ahora bien, en el animal hiperformalizado que es el hombre, «la inmensa mayoría de sus sentires son puro sentir». Pues «sentir» no es exclusivo de los órganos de los sentidos, sino que "toda célula siente a su modo" y la transmisión nerviosa es un auténtico sentir. Sin embargo, ninguna de estas funciones constituye un "hacerse cargo de la situación», ni contiene una impresión de realidad ${ }^{75}$. Pues si el hombre tuviera que hacerse cargo de cada transmisión sináptica, no podría vivir. Hay, pues, un puro sentir que no es intelectivo. Pero, en cierto nivel, cuando faltan las respuestas adecuadas al estímulo, el hombre se hace cargo de la situación, siente la realidad, intelige sentientemente lo real. He aquí el «fenómeno de la intelección sentiente» ${ }^{76}$, un acto de intelección a partir de la unidad estructural de sentir e inteligir, que no es impasible, ni tampoco un acto de comprensión, sino impresión de realidad. La apertura de la esencia intelectiva no es primariamente comprensión, sino que se halla vertida al sentir: la apertura es impresión ${ }^{77}$.

\subsection{Cerebro e inteligencia}

Además de la homeostasis ( «homeostasia») como mecanismo de estabilidad del medio interior, en Acerca del mundo ${ }^{78}$ Zubiri expone la decisiva importancia del sistema nervioso en el proceso hominizador, hasta la configuración del cerebro hiperformalizado, que es la base biológica de la inteligencia y ésta, de la

73 Ibidem, 106.

74 ZuBIRI, X., Inteligencia sentiente. Madrid: Alianza, 1980.

75 Ibídem, 114.

76 Ibídem, 115.

77 Zubiri, X., Sobre la esencia. Nueva edición. Madrid: Alianza, 2008, 506.

78 Zubiri, X., Acerca del mundo. Madrid: Alianza, 2010, que recoge un curso de 1960, con Presentación de Antonio González. 
personificación de la vida ${ }^{79}$. Esta innovación evolutiva (según Zubiri, «irreductible») de la inteligencia otorga al hombre una nueva posición en el mundo: por un lado, el hombre forma parte del mundo y de la naturaleza (por su cuerpo); pero, en tanto que persona, dice Zubiri, «no es del mundo», de manera que el espíritu individual, que es personal, está en el mundo, pero no forma parte del mundo ${ }^{80}$.

La hiperformalización del cerebro es una innovación en el Universo, que posibilita concebir al hombre como animal de realidades, pero también como esencia abierta y como persona. El hombre es animal de realidades y de ello resulta que es animal personal. Estructuralmente es personeidad, pero lo es animalmente $^{81}$. El hombre es estructuralmente animal de realidades y modalmente es realidad "suya», persona. La persona es una esencia abierta, sobre todo a su propia realidad, y por eso es persona. De ahí que la apertura a su propio carácter de realidad modifique (tipifique) ${ }^{82}$ el carácter «en sí» que tiene la realidad humana.

La inteligencia humana, basada en la hiperformalización del cerebro, abre a una vida hiperformalizada («hiper-misma», «suya») y ejerce dos funciones, una biológica y otra transcendental. La primera consiste en estabilizar la especie y en ser factor de respuesta adecuada en cada individuo; la segunda es la que corresponde a la apertura personal de la esencia abierta, lo cual significa también que la inteligencia es personal, «suya $»^{83}$.

Así pues, la inteligencia, por una parte, es la capacidad que tiene el hombre de hacerse cargo de la realidad, de enfrentarse a las cosas como realidades, y que lo caracteriza como animal de realidades ${ }^{84}$. Pero la esencia inteligente que es el hombre determina un modo de realidad, es decir, tiene una función transcendental. En virtud de una nota suya, la inteligencia, se constituye un tipo de realidad: la realidad en que la realidad se abre a sí misma, es decir, esencia abierta con apertura personal ${ }^{85}$. La persona es la forma de realidad del hombre ${ }^{86}$.

Esta forma de realidad personal que es el hombre consta de un sistema de notas, entre las que sobresale especialmente la inteligencia, en conexión esencial con el sentimiento y la voluntad. Son unas notas en virtud de las cuales el hombre es una realidad psico-orgánica ${ }^{87}$. Por una parte, el hombre es un ser viviente, un animal que se comporta con las cosas y consigo mismo en tanto

$79 \quad$ Ibídem, p. 175.

$80 \quad$ Ibídem, p. 199.

81 ZuBiri, X., Sobre la esencia, 507.

82 Ibídem, 502; ZuBIRI, X., Estructura dinámica de la realidad. Madrid: Alianza, 1989, con Presentación de Diego Gracia, 207 y 208.

83 ZuBiRI, X., Estructura dinámica de la realidad, 217.

84 Ibídem, 218.

85 Ibidem, 221.

86 Ibídem, 243.

87 ZuBIRI, X., Tres dimensiones del ser humano: individual, social, histórica. Madrid: Alianza, 1974, con Presentación de Jordi Corominas, 7. 
que realidades: es animal de realidades, vive de la realidad ${ }^{88}$. Pero asimismo el hombre es un sistema psico-orgánico, cuyo carácter o forma de realidad es ser persona, animal personal ${ }^{89}$.

La realidad humana es para sí misma no sólo un sistema de notas que «de suyo» la constituyen, sino que es ante todo la realidad que le es propia en cuanto realidad. El hombre tiene como forma de realidad la suidad. Ésta es la que constituye la razón formal de la personeidad, no la subsistencia. Ser persona no consiste simplemente en ser una realidad inteligente y libre ${ }^{90}$; tampoco en ser sujeto de sus actos. Se es persona por el hecho de ser realidad humana, esto es, de tener inteligencia. Esa inteligencia y personeidad se adquiere en algún momento del proceso genético de hominización, que es casi imposible de definir ${ }^{11}$. Pero desde el punto de vista de su forma de realidad, el hombre es persona, es animal personal. Y es la inteligencia sentiente en función transcendental la que determina esa forma de realidad que Zubiri llama personeidad. Por consiguiente, desde el punto de vista de las propiedades que posee, el hombre es animal de realidades; y, desde el punto de vista de su forma de realidad, es animal personal, animal dotado de suidad ${ }^{92}$.

En definitiva, el hombre es persona por poseer inteligencia sentiente, cuyo acto formal es impresión de realidad ${ }^{93}$. Se trata de una «intelección cerebral» o de un "cerebro inteligente»" ${ }^{94}$, una intelección sentiente o un sentir intelectivo; un proceso donde todo lo psíquico es somático y lo somático es psíquico, en el que lo cerebral y lo intelectivo constituyen una sola actividad cerebral, la cual por su inespecifidad neurofuncional tiene dos momentos, el neurofuncional y el intelectivo ${ }^{95}$, a cuya unidad y conexión dedica Zubiri los Apéndices de la versión más madura de su noología en Inteligencia sentiente.

Universidad de Valencia

Jesús Conill SAncho

Jesus.Conill@uv.es

[Artículo aprobado para publicación en este número extraordinario en noviembre de 2014]

${ }^{88} \quad$ Ibídem, p. 106.

89 Ibídem, 8 y 106. Vid. también Zubiri, X., Inteligencia sentiente, 108-109, 165, 180.

90 ZuBiri, X., El hombre y Dios. Nueva edición, 58 y 353.

91 Ibidem, p. 60.

92 Ibídem, p. 353.

93 Ibidem, p. 89.

94 Zubiri, X., Sobre el hombre, 465.

95 Ibidem, p. 526. 
